\title{
Estabilidade aeróbia da ração total e de silagens de capim-marandu tratadas com aditivos químicos e bacterianos
}

\author{
Thiago Fernandes Bernardes ${ }^{1}$, Ricardo Andrade Reis ${ }^{2}$, Gustavo Rezende Siqueira ${ }^{3}$, Rafael \\ Camargo do Amaral ${ }^{4}$, Aureliano José Vieira Pires ${ }^{5}$
}

\footnotetext{
${ }^{1}$ Pós-doutorando - ESALQ/USP. Bolsista FAPESP.

2 Departamento de Zootecnia - FCAVIUNESP - Jaboticabal, SP.

3 Apta - Pólo Regional da Alta Mogiana - Colina, SP.

${ }^{4}$ Mestrando em Ciência Animal e Pastagens - ESALQ/USP. Bolsista FAPESP.

${ }^{5}$ Departamento de Tecnologia Rural e Animal - UESB - Itapetininga, BA.
}

RESUMO - Esta pesquisa foi realizada com o objetivo de determinar o efeito da inclusão de aditivo químico e da inoculação de bactérias homo e heterofermentativas sobre a estabilidade aeróbia de silagens de capim-marandu e da ração total. Foram conduzidos três experimentos para avaliação do benzoato de sódio e de dois inoculantes, um contendo Lactobacillus plantarum + Propionibacterium e o segundo Lactobacillus buchneri. Após 60 dias de fermentação, os silos foram abertos e as silagens e a ração total (RT) contendo silagens de capim-marandu foram colocadas em caixas de isopor e transferidas para câmara climática, a $25 \pm 1^{\circ} \mathrm{C}$, para determinação das variações de temperatura na ração total e na silagem, das recuperações de MS e das alterações no $\mathrm{pH}$ da silagem. O delineamento experimental foi o inteiramente casualizado, em esquema de parcelas subdivididas. Houve perdas de MS e elevação dos teores de pH quando as silagens foram colocadas em condições de aerobiose. A temperatura das silagens e da RT teve discreto aumento durante os seis dias de aeração. O uso de bactérias ou de benzoato de sódio não influenciou a estabilidade aeróbia das silagens.

Palavras-chave: benzoato de sódio, Brachiaria brizantha, inoculante, L. buchneri, perdas

\section{Aerobic stability of total mixed ration and marandugrass silage using microbial or chemical additive}

\begin{abstract}
This research evaluated the inclusion of chemical additive and the inoculation with homo and heterofermentative bacteria on the aerobic stability of the Marandu grass silages and on the total mixed ration (TMR). It was conducted three experiments to evaluate sodium benzoate and two inoculants: 1. Lactobacillus plantarum + Propionibacterium and; 2. Lactobacillus buchneri. The silos were opened after 60 days of fermentation; the silages and the TMR containing the silages were placed in a polystyrene box, and transferred to a climatic chamber kept at $25 \pm 1^{\circ} \mathrm{C}$ to determine the temperature changes, dry matter recovery, and $\mathrm{pH}$ values. The data were analyzed according to a complete randomized design, in a split plot arrangement. The silages showed $\mathrm{DM}$ losses and increasing $\mathrm{pH}$ during the air exposure phase. The silages and TMR temperatures showed a slight increase during the six days of air exposure. Bacteria inoculants or sodium benzoate didn't affect the silage aerobic stability.
\end{abstract}

Key Words: Brachiaria brizantha, inoculant, Lactobacillus buchneri, losses, sodium benzoate

\section{Introdução}

A deterioração aeróbia, fenômeno decorrente da penetração de ar no silo, é um dos principais entraves no processo de produção de silagens. O oxigênio pode penetrar na massa mesmo quando o silo se encontra fechado, mas, sobretudo durante a fase de desabastecimento e fornecimento da silagem aos animais (Bernardes et al., 2005; Siqueira et al., 2005). A presença de oxigênio na face do silo e seu respectivo avanço para as camadas internas durante sua utilização determinam a multiplicação de alguns grupos de microrganismos aeróbios que consomem os compostos energéticos presentes na silagem (Pahlow et al., 2003), o que eleva as perdas de MS e do valor nutritivo, repercutindo negativamente sobre o desempenho produtivo dos animais.

Desde a década de 80, são utilizados no Brasil aditivos microbianos formulados com bactérias de espécies como Streptococcus faecium, Pediococcus acidilactici e Lactobacillus plantarum, cujos princípios de atuação 
são aumentar a produção de ácido lático e promover a rápida redução do pH da massa ensilada (Costa et al., 2001). A inoculação com bactérias homoláticas é feita com os objetivos de reduzir as fermentações clostrídicas e tornar o processo fermentativo mais eficiente (Driehuis et al., 1997). Essa prática tem sido recomendada principalmente para capins tropicais, tendo em vista as rotas fermentativas indesejáveis sofridas por essas espécies (Nussio et al., 2002; Reis et al., 2004). Segundo Pereira et al. (2002), os resultados com inoculantes contento bactérias homoláticas em forrageiras tropicais têm sido pouco consistentes e conclusivos.

Os nutrientes preservados e/ou produzidos durante a fermentação pela presença de bactérias homoláticas (ácido lático) podem ser consumidos quando o silo é aberto (Muck, 2004), pois o lactato pode servir de substrato para os microrganismos deterioradores, o que determinaria a redução da estabilidade aeróbia dessas silagens (Kung et al., 2003). O acréscimo de outros ácidos, como o acético, o propiônico e o butírico, poderia aumentar a estabilidade, pois são inibidores de microrganismos deterioradores (Moon, 1983), o que ocorre naturalmente em silagens de capins tropicais, em decorrência das fermentações inadequadas (Andrade \& Melotti, 2003; Silva et al., 2005).

A bactéria Lactobacillus buchneri (Weinberg \& Muck, 1996), originada do isolamento natural em silagens aerobicamente estáveis, produz durante a fermentação os ácidos lático, acético e 1,2 propanodiol. $\mathrm{O}$ acetato produzido tem função inibidora sobre espécies de microrganismos deterioradores (leveduras e fungos) que crescem quando a silagem é exposta ao ambiente (Driehuis et al., 1999; Oude Elfererink et al., 2001).

No intuito de diminuir as perdas de nutrientes durante a exposição das silagens ao oxigênio, agentes conservantes utilizados na indústria alimentícia têm sido testados para o controle de qualidade de alimentos para os animais, como é o caso do benzoato de sódio. O ácido benzóico $\left(\mathrm{C}_{6} \mathrm{H}_{5} \mathrm{COOH}\right)$ é um produto granulado em pó, comercializado na forma de benzoato de sódio $\left(\mathrm{C}_{6} \mathrm{H}_{5} \mathrm{COONa}\right)$ pelo fato de o sódio possuir alta solubilidade em água (500 g/L), enquanto o ácido, geralmente utilizado como agente conservante, possui solubilidade de 3,4 g/L (Pölönen, 2000).

No passado, a inclusão de ácidos em silagens era feita em altas doses (10 a $20 \mathrm{~g} / \mathrm{kg}$ ), o que geralmente provocava a esterilização do alimento, prejudicando o processo fermentativo. Além disso, o ácido é corrosivo ao equipamento empregado na sua aplicação (Kung et al., 2003). Atualmente, o benzoato tem sido utilizado como controlador da qualidade de alimentos para os animais, geralmente em associação a outros ácidos, como o propiônico e o fórmico, em concentrações de 0,5 a 2 g/kg (Pölönen, 2000).

Nesta pesquisa, avaliaram-se inoculantes contendo bactérias homo e heterofermentativas e o uso de benzoato de sódio no controle de perdas de silagens de capimmarandu durante a exposição ao ambiente.

\section{Material e Métodos}

Os experimentos foram conduzidos em Jaboticabal, SP, a $21^{\circ} 15^{\prime} 22^{\prime \prime}$ S e $48^{\circ} 18^{\prime} 58^{\prime \prime}$ W e a uma altitude de $595 \mathrm{~m}$. No experimento 1, o capim-marandu, Brachiaria brizantha (Hochst ex. A. Rich) Stapf cv. Marandu, foi colhido em 12 de novembro de 2003, aos 58 dias de crescimento vegetativo, utilizando-se colhedora marca Casale ${ }^{\circledR}$ modelo CFC 2000.

A forragem colhida foi ensilada diretamente após o corte, sem aplicação de aditivo (controle), ou com aplicação de 0,$5 ; 1 ; 2$; ou $3 \mathrm{~g} / \mathrm{kg}$ de benzoato de sódio. $\mathrm{O}$ aditivo foi aplicado antes do enchimento dos silos, na forma de solução aquosa, por meio de pulverizador manual, buscando-se distribuição uniforme na massa de forragem.

Utilizaram-se como silos experimentais baldes de plástico com capacidade para 7,5 L. A compactação foi realizada por meio de bastões de ferro, com acomodação de camadas de aproximadamente $5 \mathrm{~cm}$ de espessura atingindo densidade média de $116 \mathrm{~kg}$ de $\mathrm{MS} / \mathrm{m}^{3}$.

No experimento 2 , a colheita da forragem foi realizada no dia 13 de dezembro de 2003, quando o capim apresentava 50 dias de crescimento vegetativo, utilizando-se colhedora marca Casale ${ }^{\circledR}$, modelo CFC 2000. A forragem foi ensilada diretamente após o corte, sem aplicação de aditivo (Controle); ou com a aplicação de Lactobacillus plantarum cepa MA 18/5U + Propionibacterium cepa MS01; 1 g/kg de benzoato de sódio; ou Lactobacillus buchneri cepa NCIMB 40788. Os aditivos foram aplicados na forma de solução aquosa, por meio de pulverizador manual. O inoculante contendo L. plantarum + Propionibacterium utilizado foi o Propiolact ${ }^{\circledR}$, aplicado na dose de $1,5 \times 10^{5}$ ufc/g de forragem fresca (1 $\mathrm{g}$ do inoculante/200 kg de forragem verde - garantia de $3,0 \times 10^{10}$ bactérias/g de produto, segundo o fabricante). O produto contendo L. buchneri foi o Lalsil ${ }^{\circledR}$, aplicado na concentração de 5,0 x $10^{4} \mathrm{ufc} / \mathrm{g}$ de forragem fresca (1 $\mathrm{g}$ do inoculante/500 $\mathrm{kg}$ de forragem verde - garantia $2,5 \times 10^{10}$ bactérias/g de produto, segundo o fabricante).

Utilizaram-se como silos experimentais baldes de plástico com capacidade de 7,5 L. A compactação foi realizada por meio de bastões de ferro, com acomodação de camadas de aproximadamente $5 \mathrm{~cm}$ de espessura, em densidade média de $120 \mathrm{~kg}$ de $\mathrm{MS} / \mathrm{m}^{3}$. 
No experimento 3, o capim foi colhido utilizando-se colhedora marca Casale ${ }^{\circledR}$, modelo CFC 2000, no dia 10 de janeiro de 2004, quando apresentava 53 dias de crescimento vegetativo.

A forragem colhida foi submetida ao emurchecimento visando obter teores crescentes de MS. O monitoramento do material exposto no campo foi realizado utilizando-se forno de microondas, segundo metodologia descrita por Souza (2003). Desse modo, os tratamentos avaliados foram: 200 g/kg MS com (200CLB) ou sem (200SLB) L. buchneri; $300 \mathrm{~g} / \mathrm{kg}$ MS com (300CLB) ou sem (300SLB) L. buchneri; e $350 \mathrm{~g} / \mathrm{kg}$ MS com (350SLB) ou sem (350CLB) L. buchneri.

O inoculante utilizado foi o Lalsil ${ }^{\circledR}$ contendo L. buchneri (cepa NCIMB 40788) e sua aplicação foi na forma de solução aquosa, por meio de pulverizador, buscando-se distribuição uniforme na massa de forragem. A concentração adotada foi de $5,0 \times 10^{4} \mathrm{ufc} / \mathrm{g}$ de forragem fresca (1 g do inoculante/ $500 \mathrm{~kg}$ de forragem verde - garantia $2,5 \times 10^{10}$ bactérias/g de produto, segundo o fabricante).

Utilizaram-se como silos experimentais baldes de plástico com capacidade de 7,5 L. A compactação foi realizada com acomodação de camadas de aproximadamente $5 \mathrm{~cm}$ de espessura, em densidades de 116 (200 e 200 CLB), 174 (300 SLB e 300 CLB) e $203 \mathrm{~kg} \mathrm{MS} / \mathrm{m}^{3}$ ( 350 SLB e 350 CLB).

Nos experimentos 1 , 2 e 3 , quando decorridos 60 dias de fermentação, os silos foram abertos e todo o seu conteúdo foi transferido para bandejas de plástico para posterior homogeneização. Após este procedimento, amostras de silagem $(1,5 \mathrm{~kg})$ foram colocadas em caixas de isopor e transferidas para câmara climática a $25 \pm 1^{\circ} \mathrm{C}$. As temperaturas das silagens foram obtidas duas vezes ao dia, durante seis dias, com o uso de termômetro inserido a $10 \mathrm{~cm}$, no centro da massa. A temperatura ambiente foi controlada pelo termostato do aparelho refrigerador e também por meio de termômetros suspensos no ar. A instabilidade aeróbia foi calculada como o tempo para que a temperatura do alimento, após a abertura do silo, apresentasse elevação de $2^{\circ} \mathrm{C}$ em relação à temperatura ambiente (Moran et al., 1996). Também como medida física foi avaliada a recuperação de MS (RMS) em aerobiose ao final de seis dias de exposição ao ambiente, de acordo com a seguinte equação:

$$
R M S=\left(\frac{M F f x M S f}{M F i x M S i}\right) x 100
$$

em que: RMS = recuperação de MS (\%); $\mathrm{MFi}$ = massa de forragem inicial (kg); MSi = teor de MS inicial (\%); MFf = massa de forragem final (kg); MSf = teor de MS final (\%).

Em outro conjunto de caixas de isopor, foi colocada a mesma quantidade de silagem $(1,5 \mathrm{~kg})$. As caixas foram levadas à câmara climática para determinação das alterações de pH em amostras com 0, 2, 4 e 6 dias de aeração.

Ainda, em outro conjunto de recipientes, foi determinada a instabilidade aeróbia da ração total (RT) contendo silagem de capim-marandu, de acordo com os respectivos tratamentos. A dieta foi calculada segundo o NRC - gado de corte (1996) para novilhos Nelore com peso médio inicial de 350 kg de PV e ganho médio diário de 1,1kg, com as seguintes participações dos ingredientes: silagem de capim-marandu (50\%), milho grão moído (40,25\%), farelo de soja (9\%) e suplemento mineral $(0,77 \%)$.

No experimento 1, primeiramente foi realizado o teste $\mathrm{F}$ para identificação da significância dos tratamentos e de suas interações. Uma vez que as concentrações de benzoato de sódio constituem uma variável quantitativa, foi realizada análise de regressão. No entanto, as variáveis não apresentaram equações significativas ou com coeficiente de determinação $\left(\mathrm{r}^{2}\right)$ alto, portanto, procedeu-se ao teste Tukey $(\mathrm{P}<0,05)$ para comparação de médias.

O delineamento experimental utilizado para os três experimentos foi o inteiramente casualizado com quatro (experimento 2) ou três repetições (experimentos 1 e 3) utilizando-se o esquema de parcelas subdivididas, em que os fatores das parcelas foram os tratamentos e o fator atribuído à subparcela, o tempo de exposição ao oxigênio. Os dados foram analisados pelo programa ESTAT, utilizando-se os procedimentos da análise de variância, e as médias comparadas pelo teste Tukey $(\mathrm{P}<0,05)$.

\section{Resultados e Discussão}

Constam nas Tabelas 1 e 2 as equações de regressão referentes ao experimento 1 . Não foram encontrados significância ou coeficientes de determinação adequados que justificassem o uso das equações de regressão. Para isso, em virtude dos baixos coeficientes de determinação, que traduzem pouca confiabilidade na utilização das equações encontradas, aplicou-se o teste de médias na avaliação de variáveis quantitativas, mesmo considerando o trabalho de Cardellino \& Siewerdt (1992), que aponta ser incorreta a utilização desse teste.

A presença de benzoato de sódio nas concentrações de 0,5; 1 e $2 \mathrm{~g} / \mathrm{kg}$, em comparação aos demais tratamentos, reduziu os teores de amônia (Tabela 3 ) no momento da abertura dos silos (tempo 0 ), porém, não promoveu diferença significativa $(\mathrm{P}>0,05)$ entre as silagens.

O aumento da concentração de benzoato provocou decréscimo, de 5,0 para 4,6 (nas doses de 0 e $3 \mathrm{~g} / \mathrm{kg}$, respectivamente), dos valores de $\mathrm{pH}$ (Tabela 3 ) no momento da abertura dos silos $(\mathrm{P}<0,05)$. Com o avançar do tempo 
Tabela 1 - Características das equações de regressão linear (experimento 1)

Table 1 - Characteristics of linear regression equations (experiment 1)

Variável

Variable

Equação de regressão ${ }^{1}$
Regression equation

$\mathrm{P}<$

b

$\mathrm{P}<\mathrm{F}$

Em função da concentração de benzoato de sódio As a function of the sodium benzoate level

MS (g/kg) (DM, g/kg)

$\mathrm{NH}_{3}\left(\mathrm{~g} / \mathrm{kg} \mathrm{N}\right.$ total) $\left(\mathrm{NH}_{3}, \mathrm{~g} / \mathrm{kg}\right.$ total $\left.\mathrm{N}\right)$

$\mathrm{pH}$

RMS (\%) (DMR, \%)

Temperatura DT $\left({ }^{\circ} \mathrm{C}\right)\left(T M R\right.$ temperature, $\left.{ }^{\circ} \mathrm{C}\right)$
20,722

113,051

5, 247

94,836

24,387
$* *$

$* * \quad-2,655$

$* * \quad-0,162$

* $\quad 0,289$

** $\quad 0,183$
0,67

0,80

$* *$

0,69

0,18
0,01

0,01

0,48

0,01

0,03

Em função do tempo de exposição aeróbica As a function of the aerobic exposure time

$\begin{array}{lrrrr}\mathrm{pH} & 4,925 & * * & 0,037 & 0,11 \\ \text { Temperatura DT }\left({ }^{\circ} \mathrm{C}\right)\left(\mathrm{TMR} \text { temperature, }{ }^{\circ} \mathrm{C}\right) & 23,940 & * * & 0,228 & * *\end{array}$

$1 \mathrm{a}=$ intercepto; $\mathrm{b}=$ coeficiente linear; $\mathrm{r}^{2}=$ coeficiente de determinação.

$1 \mathrm{a}=$ intercept; $b=$ slope; $r^{2}=$ correlation coefficient.

Tabela 2 - Características das equações de regressão quadrática (experimento 1)

Table 2 - Characteristics of quadratic regression equations (experiment 1)

\begin{tabular}{|c|c|c|c|c|c|c|c|}
\hline \multirow[t]{2}{*}{$\begin{array}{l}\text { Variável } \\
\text { Variable }\end{array}$} & \multicolumn{7}{|c|}{$\begin{array}{c}\text { Equação de regressão }{ }^{1} \\
\text { Regression equation }\end{array}$} \\
\hline & $\mathrm{a}$ & $\mathrm{P}<\mathrm{F}$ & $\mathrm{b}$ & $\mathrm{P}<\mathrm{F}$ & C & $\mathrm{P}<\mathrm{F}$ & $r^{2}$ \\
\hline
\end{tabular}

Em função da concentração de benzoato de sódio As a function of the sodium benzoate level

MS $(\mathrm{g} / \mathrm{kg})(D M, \mathrm{~g} / \mathrm{kg})$

$\mathrm{NH}_{3}\left(\mathrm{~g} / \mathrm{kg} \mathrm{N}\right.$ total) $\left(\mathrm{NH}_{3}, \mathrm{~g} / \mathrm{kg}\right.$ total $\left.\mathrm{N}\right)$

$\mathrm{pH}$

RMS (\%) (DMR, \%)

Temperatura DT $\left({ }^{\circ} \mathrm{C}\right)\left(\mathrm{TMR}\right.$ temperature, $\left.{ }^{\circ} \mathrm{C}\right)$
21,931

87,444

5,195

94,431

24,470
$* * \quad-3,187$

** 68,322

** $\quad-0,018$

** $\quad 1,401$

** $\quad-0,047$

$* *$
0,07
0,83
0,62
0,93

1,104

$-23,390$

$-0,047$

$-0,366$

0,076
** $\quad 0,47$

0,06

0,07

0,68

0,65

0,28

0,51

0,02

0,03

Em função do tempo de exposição aeróbia As a function of the aerobic exposure time

$\mathrm{pH}$ 4,901

Temperatura DT $\left({ }^{\circ} \mathrm{C}\right)$ (TMR temperature, $\left.{ }^{\circ} \mathrm{C}\right)$

23, 915

** $\quad 0,072$

0,266

0,15

$-0,006$

$-0,006$

0,46

0,85

0,12

$1 \mathrm{a}=$ intercepto; $\mathrm{b}=$ coeficiente linear; $\mathrm{r}^{2}=$ coeficiente de determinação.

${ }^{1} \mathrm{a}=$ intercept; $b=$ slope; $r^{2}=$ correlation coefficient.

de exposição ao ar, houve acréscimo dos valores de $\mathrm{pH}$ $(\mathrm{P}<0,05)$ em todas as silagens estudadas. A média no dia 0 foi de 4,9 e, no dia 6, de 5,1, com aumento médio de $6 \%$ entre o primeiro e o último dia de exposição aeróbia, comprovando, portanto, que os ácidos orgânicos podem ter sido consumidos (principalmente o lático) durante o processo de deterioração, pois alguns microrganismos os utilizam como fonte de energia (Pahlow et al., 2003).

As silagens com 1,2 ou $3 \mathrm{~g} / \mathrm{kg}$ desse aditivo apresentaram menores perdas de MS (3,4; 5,0 e 4,4\%, respectivamente) em comparação àquelas com 0 e 0,5 g/kg, porém, não foram estatisticamente diferentes.

O provável motivo para a aplicação do aditivo ter causado efeito discreto sobre os processos fermentativo e de deterioração das silagens foi o valor de $\mathrm{pK}_{\mathrm{a}}$ do ácido $(4,2)$. Quando os valores de $\mathrm{pH}$ são superiores aos de $\mathrm{pK}_{\mathrm{a}}$, reduzem a eficiência do ácido na solução, pois diminui a forma ácida e predomina a forma ionizada. Desse modo, o efeito inibitório do aditivo sobre os microrganismos é reduzido em alimentos com $\mathrm{pH}$ acima de 4,2, como pode observado neste estudo. Segundo McDonald et al. (1991), o ácido em $\mathrm{pH}$ inferior ao seu $\mathrm{pK}_{\mathrm{a}}$ permanece na forma não dissociada (ácida). Uma vez que a membrana dos microrganismos é permeável a esses ácidos, após sua entrada via transporte passivo dentro da célula, o ácido é dissociado $\left(\mathrm{RCOO}^{-}+\mathrm{H}^{+}\right)$, pois o $\mathrm{pH}$ interno do microrganismo é de 7,0 (superior ao $\mathrm{pK}_{\mathrm{a}}$ ), liberando íons $\mathrm{H}^{+}$. Conseqüentemente, ocorre rápida redução do $\mathrm{pH}$ intracelular, retardando o 
Tabela 3 - Estabilidade aeróbia da ração total e composição das silagens tratadas com diferentes concentrações de benzoato de sódio $(0 ; 0,5 ; 1 ; 2$ e $3 \mathrm{~g} / \mathrm{kg})$, durante a exposição ao ar (experimento 1)

Table 3 - Aerobic stability of total mixed ration and composition of silages treated with different levels of sodium benzoate $(0,0.5,1,2$, and $3 \mathrm{~g} / \mathrm{kg})$, during aerobic exposure (experiment 1)

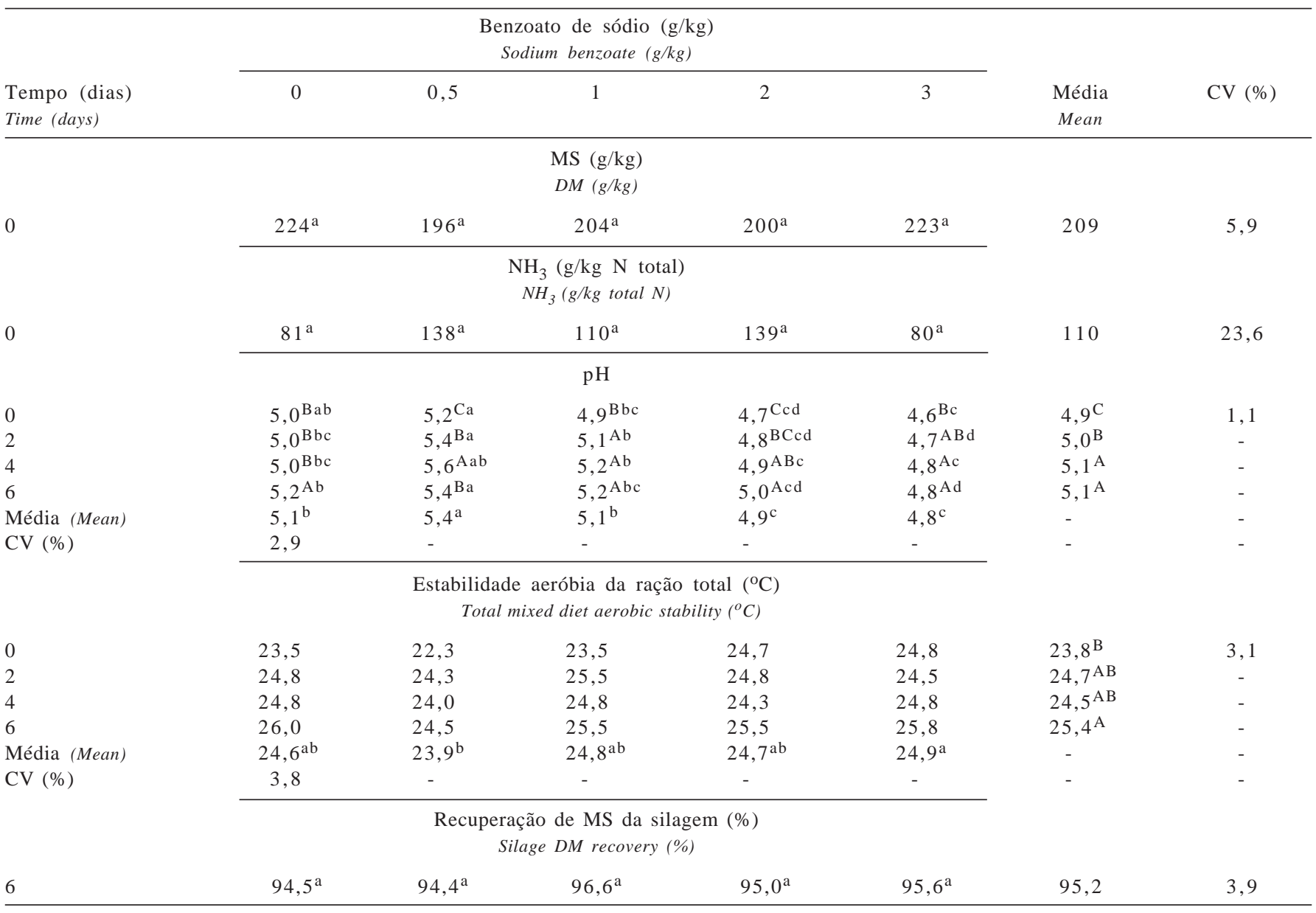

Médias seguidas de mesmas letras, maiúsculas nas colunas e minúsculas nas linhas, não diferem $(P>0,05)$ pelo teste Tukey; CV = coeficiente de variação. Means followed by same letters, capital letters in the columns and lower cases in the rows, do not differ $(P>0.05)$ by Tukey test; CV = coefficient of variation.

crescimento e podendo causar a morte celular. Woolford (1975) avaliou o efeito do benzoato em diferentes valores de pH e observou que, conforme o $\mathrm{pH}$ diminuiu, a necessidade do aditivo na inibição de leveduras e fungos também foi reduzida. Em pH 6, são necessários, respectivamente, 110 e $55 \mathrm{mM}$ de benzoato de sódio para inibir leveduras e fungos filamentosos.

No experimento 2, quando os silos foram abertos, os teores médios de MS das silagens foram 240, 246, 206 e $250 \mathrm{~g} / \mathrm{kg}$ para as silagens controle e com L. plantarum + Propionibacterium, benzoato e $L$. buchneri, respectivamente $(\mathrm{P}<0,05)$. A adição de ácidos durante a ensilagem pode provocar maior rompimento de células dos tecidos da planta durante a fermentação e esse rompimento seria, possivelmente, o fator para que as silagens tratadas com benzoato apresentassem os menores teores de MS (Tabela 4).

Os valores de $\mathrm{pH}$ (Tabela 4) no momento da abertura dos silos nas silagens controle e acrescidas de $L$. plantarum
+ Propionibacterium foram inferiores aos obtidos nas silagens tratadas com benzoato e L. buchneri. A rota heterolática de fermentação do L. buchneri promove menor acidez na massa ensilada, pois produz, além de ácido lático, acetato e 1,2 propanodiol, que são pouco eficientes na redução do pH. Além disso, o L. buchneri pode converter anaerobicamente o ácido lático presente na massa ensilada em ácido acético, 1,2 propanodiol e $\mathrm{CO}_{2}$ quando a bactéria encontra situações adversas, mantendo dessa forma a viabilidade da célula (Oude Elferink et al., 2001).

Com a aeração das silagens, houve elevação dos valores de $\mathrm{pH}(\mathrm{P}<0,05)$; as silagens controle e com benzoato sofreram as menores elevações do $\mathrm{pH}$, enquanto aquelas com L. buchneri apresentaram os maiores aumentos.

Os teores de $\mathrm{NH}_{3}$ tiveram comportamento semelhante aos valores de $\mathrm{pH}$ no momento da abertura dos silos (Tabela 4). As silagens controle e com L. plantarum + 
Tabela 4 - Estabilidade aeróbia durante a exposição ao ar da ração total e composição das silagens tratadas com diferentes aditivos (experimento 2)

Table 4 - $\quad$ Aerobic stability of total mixed ration and composition of silage treated with different additives during aerobic exposure (experiment 2)

\begin{tabular}{|c|c|c|c|c|c|c|c|}
\hline $\begin{array}{l}\text { Tempo (dias) } \\
\text { Time (days) }\end{array}$ & $\begin{array}{l}\text { Controle } \\
\text { Control }\end{array}$ & L. plantarum & + Propionibacterium & $\begin{array}{l}\text { Benzoato de sódio }(1 \mathrm{~g} / \mathrm{kg}) \\
\text { Sodium benzoate }(1 \mathrm{~g} / \mathrm{kg})\end{array}$ & L. buchneri & $\begin{array}{l}\text { Média } \\
\text { Mean }\end{array}$ & CV (\%) \\
\hline & & & $\begin{array}{c}\text { MS } \\
D M\end{array}$ & $\begin{array}{l}/ \mathrm{kg}) \\
/ \mathrm{kg})\end{array}$ & & & \\
\hline \multirow[t]{2}{*}{0} & $240^{\mathrm{a}}$ & & $246^{\mathrm{a}}$ & $206^{\mathrm{b}}$ & $250^{\mathrm{a}}$ & \multirow[t]{2}{*}{236} & \multirow[t]{2}{*}{6,1} \\
\hline & \multicolumn{5}{|c|}{$\begin{array}{c}\mathrm{NH}_{3}(\mathrm{~g} / \mathrm{kg} \mathrm{N} \text { total }) \\
\mathrm{NH}_{3}(\mathrm{~g} / \mathrm{kg} \text { total } \mathrm{N})\end{array}$} & & \\
\hline \multirow[t]{2}{*}{0} & $88^{a}$ & & $86^{a}$ & $109^{a}$ & $149^{\mathrm{a}}$ & 108 & 19,7 \\
\hline & \multicolumn{5}{|c|}{$\mathrm{pH}$} & & \\
\hline 0 & $4,6^{\mathrm{Aa}}$ & & $4,7^{\mathrm{Ba}}$ & $4,9^{\mathrm{Aa}}$ & $4,9^{\mathrm{Ca}}$ & $4,8^{\mathrm{B}}$ & 2,8 \\
\hline 2 & $4,7^{\mathrm{Ab}}$ & & $4,8^{\mathrm{Bab}}$ & $5,1^{\mathrm{Aa}}$ & $4,8^{\mathrm{Cab}}$ & $4,8^{\mathrm{B}}$ & - \\
\hline 4 & $4,7^{\mathrm{Ac}}$ & & $4,9^{\mathrm{ABbc}}$ & $5,1^{\mathrm{Ab}}$ & $5,8^{\mathrm{Ba}}$ & $5,1^{\mathrm{A}}$ & - \\
\hline 6 & $4,7^{\mathrm{Ac}}$ & & $5,0^{\mathrm{Abc}}$ & $5,1^{\mathrm{Ab}}$ & $6,2^{\mathrm{Aa}}$ & $5,3^{A}$ & - \\
\hline Média (Mean) & $4,7^{\mathrm{c}}$ & & $4,8^{\mathrm{bc}}$ & $5,0^{\mathrm{b}}$ & $5,4^{\mathrm{a}}$ & - & - \\
\hline \multirow[t]{2}{*}{ CV (\%) } & 5,4 & & - & - & - & - & - \\
\hline & \multicolumn{5}{|c|}{$\begin{array}{c}\text { Estabilidade aeróbia da ração total }\left({ }^{\circ} \mathrm{C}\right) \\
\text { Total mixed diet aerobic stability }\left({ }^{\circ} \mathrm{C}\right)\end{array}$} & & \\
\hline 0 & $22,9^{\mathrm{Ca}}$ & & $23,0^{\mathrm{Ba}}$ & $23,8^{\mathrm{Ca}}$ & $23,3^{\mathrm{Ba}}$ & 23,2 & 1,5 \\
\hline 2 & $24,9^{\mathrm{Ba}}$ & & $24,5^{\mathrm{ABa}}$ & $25,1^{\mathrm{ABa}}$ & $24,8^{\mathrm{Ba}}$ & 24,8 & - \\
\hline 4 & $24,9^{\mathrm{Bb}}$ & & $24,3^{\mathrm{ABb}}$ & $24,6^{\mathrm{Bb}}$ & $26,6^{\mathrm{ABa}}$ & 25,0 & - \\
\hline 6 & $25,5^{\mathrm{Ab}}$ & & $25,8^{\mathrm{Ab}}$ & $25,5^{\mathrm{Ab}}$ & $27,5^{\mathrm{Aa}}$ & 26,1 & - \\
\hline Média (Mean) & $24,7^{\mathrm{ab}}$ & & $24,5^{b}$ & $24,7^{\mathrm{ab}}$ & $25,3^{\mathrm{a}}$ & - & - \\
\hline \multirow{2}{*}{ CV (\%) } & 3,5 & & - & - & - & \multirow[t]{2}{*}{-} & \multirow[t]{2}{*}{-} \\
\hline & & & $\begin{array}{r}\text { Recuperação de } \\
\text { Silage } D M\end{array}$ & $\begin{array}{l}\text { da silagem }(\%) \\
\text { covery }(\%)\end{array}$ & & & \\
\hline 6 & $93,6^{\mathrm{a}}$ & & $93,2^{\mathrm{a}}$ & $93,2^{\mathrm{a}}$ & $92,8^{a}$ & 93,2 & 4,8 \\
\hline
\end{tabular}

Médias seguidas de mesmas letras, maiúsculas nas colunas e minúsculas nas linhas, não diferem $(P>0,05)$ pelo teste Tukey; $C V=$ coeficiente de variação. Means followed by same letters, capital letters in the columns and lower cases in the rows, do not differ $(P>0.05)$ by Tukey test; $C V=$ coefficient of variation.

Propionibacterium apresentaram valores inferiores aos obtidos naquelas com benzoato e L. buchneri.

Após seis dias de exposição aeróbia, as silagens controle e com aditivos apresentaram RMS de 93,2\%, mas os valores não diferiram significativamente. Desse modo, em silagens de capim-marandu produzidas com teores de MS de 200 a $250 \mathrm{~g} / \mathrm{kg}$, a adição de inoculantes com bactérias homo e heterofermentativas ou benzoato de sódio na concentração de $1 \mathrm{~g} / \mathrm{kg}$ parece não influenciar o controle da deterioração aeróbia.

No experimento 3 , as silagens apresentaram no momento da abertura dos silos diferentes teores de MS $(\mathrm{P}<0,05)$, com média de 195 (200SLB), 303 (300SLB), 356 (350SLB), 204 (200CLB), 306 (300CLB) e $357 \mathrm{~g} / \mathrm{kg}$ (350CLB) (Tabela 5).

Os teores de $\mathrm{NH}_{3}$ reduziram $(\mathrm{P}<0,05)$ com as crescentes concentrações de MS (Tabela 5). A adição de inoculante nas silagens com teores de MS de 200 e $350 \mathrm{~g} / \mathrm{kg}$ promoveu a redução nos teores de amônia, o que não ocorreu na silagem com teor de MS de $300 \mathrm{~g} / \mathrm{kg}$.

$\mathrm{O}$ aumento nos teores de MS promoveu redução do $\mathrm{pH}$ $(\mathrm{P}<0,05)$ tanto nas silagens com inoculante quanto naquelas produzidas sem aditivo (Tabela 5). A inclusão de $L$. buchneri provocou maiores valores de $\mathrm{pH}$ nas silagens com 200, 300 e 350 g de MS/kg), o que está de acordo com os resultados descritos por Ranjit et al. (2002), que inocularam doses crescentes de L. buchneri 40788 em silagens de milho e encontraram valores de $\mathrm{pH}$ superiores aos encontrados na silagem controle. A rota de fermentação apresentada por esta bactéria não tem a função de reduzir o $\mathrm{pH}$, haja vista sua pequena contribuição na produção de ácido lático em comparação a outras bactérias que possuem rota homolática durante a fermentação.

Com o avançar do tempo de aeração, todas as silagens apresentaram elevação do $\mathrm{pH}(\mathrm{P}<0,05)$, com média de 4,8 para o dia 0 e 5,4 para o dia 6. A silagem 200CLB destacou-se por suas médias, de 5,1 no dia 0 e 6,5 no dia 6 . Os resultados indicam que a presença de $L$. buchneri não promoveu resistência na degradação de ácidos orgânicos durante a aeração das silagens, pois os produtos da fermentação promovida por essa bactéria são eficientes no controle de fungos (Driehuis et al., 1999) e menos eficientes no controle de bactérias aeróbias, principais microrganismos 
Tabela 5 - Estabilidade aeróbia da ração total e composição durante a exposição ao ar das silagens tratadas com Lactobacillus buchneri (experimento 3)

Table 5 - $\quad$ Aerobic stability of total mixed ration and composition of silage treated with Lactobacillus buchneri during aerobic exposure (experiment 3)

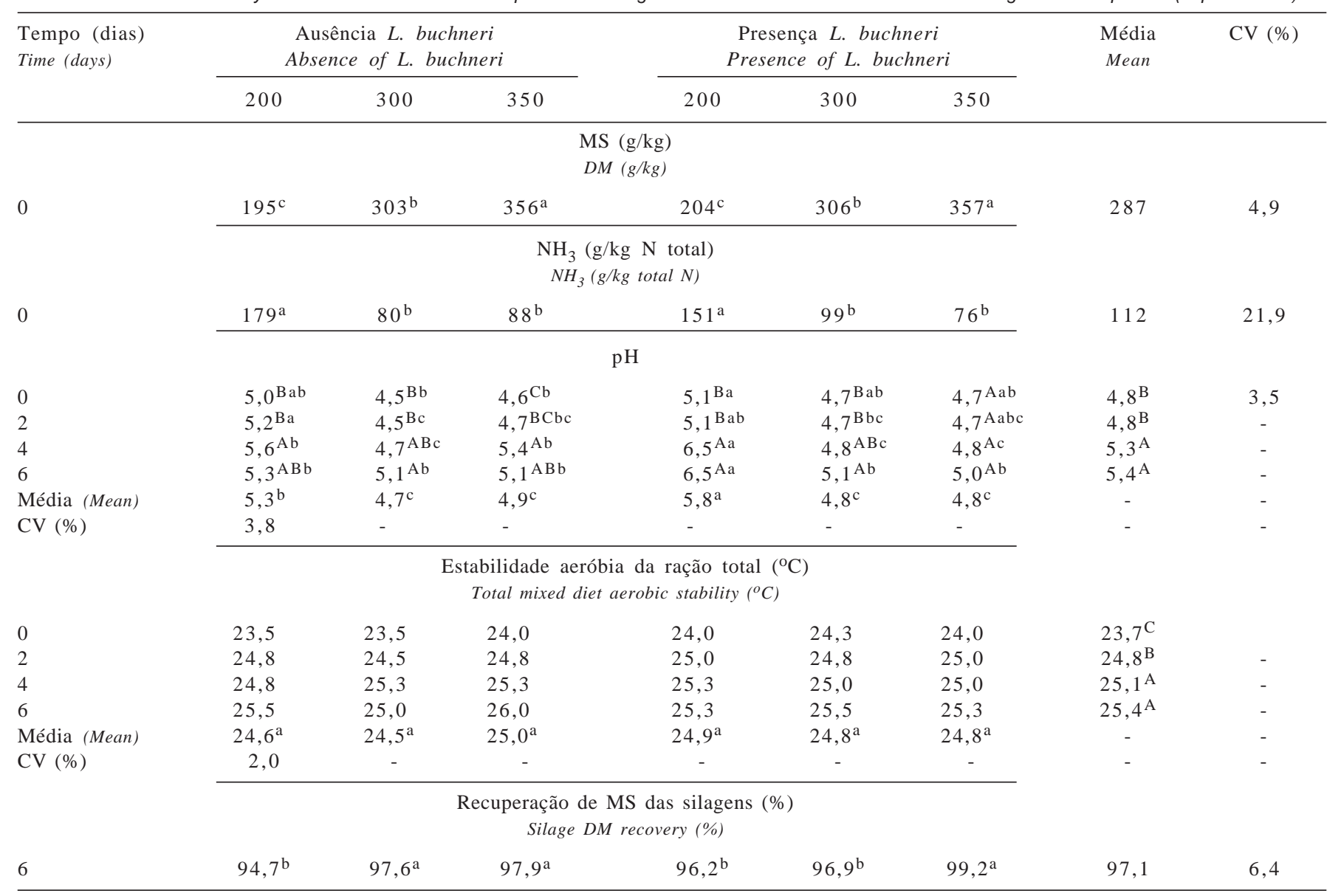

Médias seguidas de mesmas letras, maiúsculas nas colunas e minúsculas nas linhas, não diferem $(P>0,05)$ pelo teste Tukey; CV = coeficiente de variação Means followed by same letters, capital letters in the columns and lower cases in the rows, do not differ $(P>0.05)$ by Tukey test; $C V=c o e f f i c i e n t$ of variation.

deterioradores em silagens de capins tropicais (Bernardes et al., 2003). Entretanto, há relatos na literatura de que o $L$. buchneri produz um composto denominado buchnericin LB, que tem efeito bacteriostático, principalmente sobre os microrganismos Listeria monocytogenes e Bacillus cereus (Yildirim et al., 2002).

As silagens 350SLB e 350CLB tiveram as menores perdas de MS quando expostas ao ar, ao passo que aquelas com $200 \mathrm{~g} / \mathrm{kg}$, com ou sem L. buchneri, as menores recuperações.

A análise conjunta dos dados de $\mathrm{pH}$ e das perdas de MS nos experimentos 1 e 2 comprovou que as silagens de capim-marandu tratadas com aditivos microbianos não sofreram alterações no processo fermentativo e durante a deterioração aeróbia. Segundo Pahlow (1991) e Honig et al. (1999), as concentrações de bactérias inoculadas a forragem devem ser de $10^{5}-10^{6}$ células viáveis/g de forragem inoculada para que os microrganismos exógenos possam suplementar aqueles existentes na microflora epifítica, de modo que ocorram efeitos positivos em comparação à forragem não tratada, o que poderia justificar os resultados obtidos.

Andrade \& Melotti (2003) avaliaram as características fermentativas de silagem de capim-elefante (Pennisetum purpureum, Schum) tratadas com diversos inoculantes e encontraram valor de 32,3 g/kg MS de ácido acético nas silagens sem aditivo. Esses valores são considerados elevados, pois são característicos de silagens de milho inoculadas com $L$. buchneri na concentração de $1 \times 10^{6}$ bactérias/g de forragem verde (Ranjit \& Kung, 2000). Possivelmente, os incrementos nos teores de ácido acético em silagens de capins tropicais não foi necessário, tendo em vista as particularidades dessas espécies durante a fermentação.

As oscilações na temperatura das silagens durante os dias de exposição ao ar nos três experimentos estão sumarizadas na Figura 1. A temperatura das silagens estudadas pode ser considerada estável, segundo metodologia preconizada, pois não ultrapassou em $2^{\circ} \mathrm{C}$ a temperatura ambiente $\left(25^{\circ} \mathrm{C}\right)$ durante os seis dias de aeração. Ao longo 
Experimento 1

Experiment 1

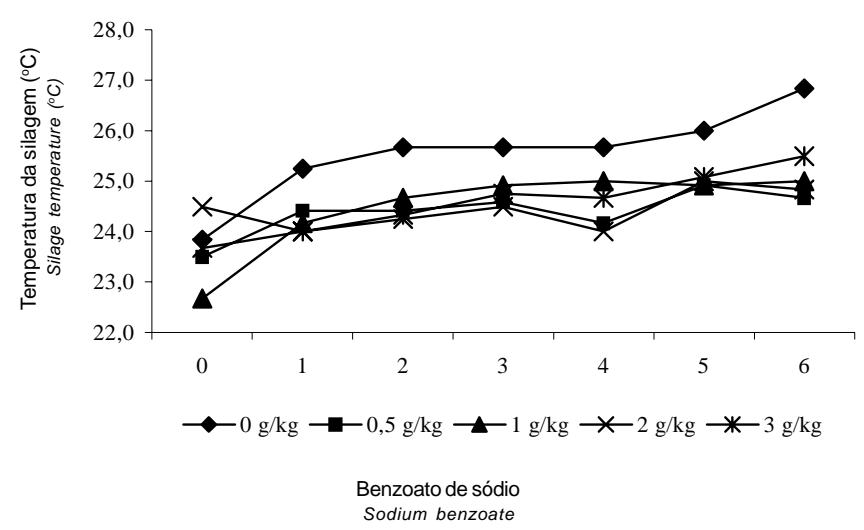

Experimento 2

Experiment 2

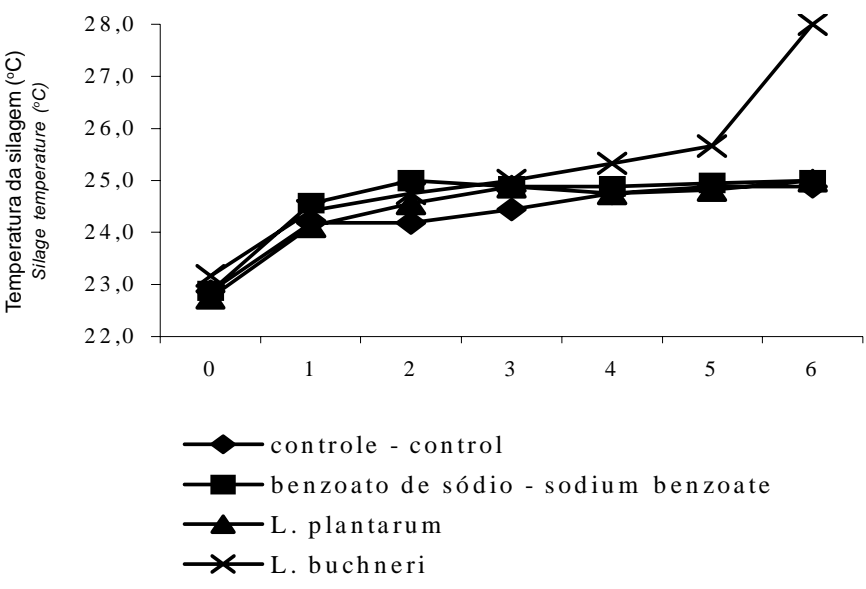

Experimento 3

Experiment 3

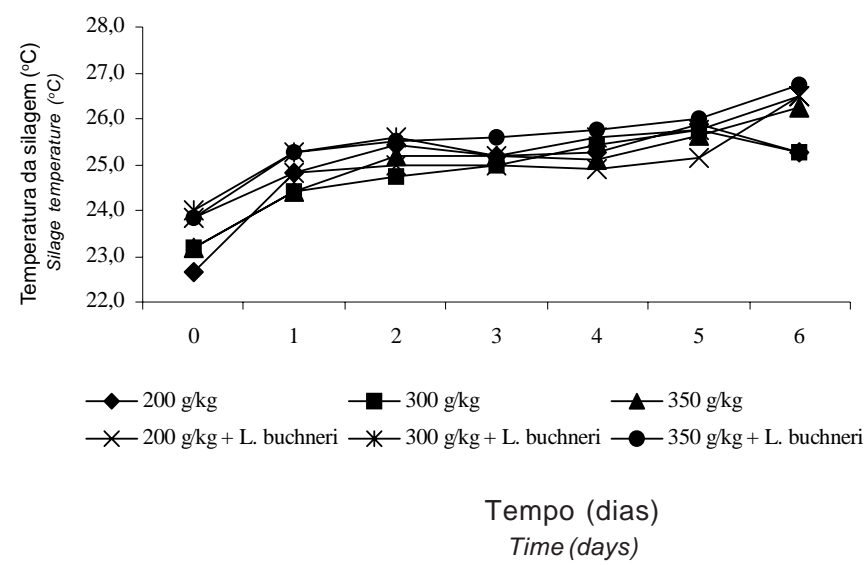

Figura 1 - Temperatura nas silagens de capim-marandu durante a exposição ao ambiente (Experimentos 1, 2 e 3).

Figure 1 - Temperature of marandugrass silages during aerobic exposure (Experiments 1, 2, and 3). do prolongamento de exposição aeróbia, houve elevação, de 23 para $27^{\circ} \mathrm{C}$, da temperatura $(\mathrm{P}<0,05)$ em todos os experimentos estudados.

O mesmo comportamento foi observado para a temperatura das rações totais (Tabelas 3, 4 e 5); não houve quebra de estabilidade durante os seis dias de aeração (temperatura acima de $27^{\circ} \mathrm{C}$ ), contudo, com o avançar do tempo de exposição ao ar, as rações apresentaram elevação de temperatura $(\mathrm{P}<0,05)$. A inclusão dos ingredientes na silagem (constituindo a RT) criou a expectativa de que a tendência da temperatura pudesse ser alterada, em razão dos maiores teores de nutrientes para os microrganismos deterioradores, contudo, essa característica não foi observada.

Silagens de capins tropicais com teores de MS abaixo de 300 g/kg são mais propensas à deterioração por bactérias aeróbias, em virtude da estabilidade de fermentação em $\mathrm{pH}$ acima de 4,5, do teor de umidade e da ausência de substrato aos microrganismos (Bernardes et al., 2003). O inverso ocorre com silagens de alta qualidade, como as de milho e as de sorgo, que são deterioradas principalmente por leveduras e fungos (Muck, 2004). Entretanto, segundo Spoelstra et al. (1988), ocasionalmente silagens de milho também podem ser deterioradas por bactérias aeróbias.

Possivelmente, silagens de capim-marandu não acumulam temperatura porque, durante o seu metabolismo, as bactérias aeróbias não produzem calor com tanta eficiência como as leveduras e os fungos (Pahlow et al., 2003), o que explica os resultados obtidos neste experimento, no qual as silagens e a ração total não sofreram redução da estabilidade durante a exposição ao ar quando considerado somente o fator temperatura.

\section{Conclusões}

O uso de benzoato de sódio e de bactérias homo e heterofermentativas não altera a estabilidade aeróbia de silagens de capim-marandu e da ração total composta dessas silagens, visto que as fermentações secundárias desta forrageira impedem a intensa proliferação de microrganismos deterioradores.

\section{Literatura Citada}

ANDRADE, S.J.T.; MELOTTI, L. Inoculantes bacterianos na ensilagem do capim-elefante (Pennisetum purpurem, Schum). Brazilian Journal of Veterinary Research and Animal Science, v.40, p.219-223, 2003.

BERNARDES, T.F.; REIS, R.A.; SCHOCKEN-ITURRINO, R.P. Dinâmica microbiológica e alterações químicas das silagens de capim-Marandu (Brachiaria brizantha cv. Marandu) após a abertura dos silos. In: REUNIÃO ANUAL DA SOCIEDADE BRASILEIRA DE ZOOTECNIA, 40., 2003, Santa Maria. 
Anais... Santa Maria: Sociedade Brasileira de Zootecnia, [2003]. (CD-ROM).

BERNARDES, T.F.; SIQUEIRA, G.R.; REIS, R.A. Importância do planejamento na produção e uso da silagem. In: EVANGELISTA, A.R.; AMARAL, P.N.C.; PADOVANI, R.F. (Eds.). Forragicultura e pastagens: temas em evidência. 5.ed. Lavras: Universidade Federal de Lavras, 2005. p.121-176.

CARDELLINO, R.A.; SIEWERDT, F. Utilização correta e incorreta dos testes de comparação de médias. Revista Brasileira de Zootecnia, v.21, p.985-995, 1992.

COSTA, C.; MONTEIRO, A.L.G.; BERTO, D.A. et al. Impacto do uso de aditivos e/ou inoculantes comerciais na qualidade de conservação e no valor alimentício de silagens. In: SIMPÓSIO SOBRE PRODUÇÃO E UTILIZAÇÃO DE FORRAGENS CONSERVADAS, 1., 2001, Maringá. Anais... Maringá: Universidade Estadual de Maringá, 2001. p.87-126.

DRIEHUIS, F.; van WIKSELAAR, P.G.; van VUUREN, A.M. et al. Effect of a bacterial inoculant on rate of fermentation and chemical composition of high dry matter grass silages. Journal of Agricultural Science, v.128, p.323-329, 1997.

DRIEHUIS, F.; OUDE ELFERINK, S.J.W.H.; SPOELSTRA, S.F. Anaerobic lactic acid degradation during ensilage of whole crop maize inoculated with Lactobacillus buchneri inhibits yeast growth and improves aerobic stability. Journal of Applied Microbiology, v.87, p.583-594, 1999.

HONIG, H.; PAHLOW, G.; THAYSEN, J. Aerobic instability: effects and possibilities for its prevention. In: INTERNATIONAL SILAGE CONFERENCE, 12., 1999, Uppsala. Proceedings... Uppsala: Swedish University of Agricultural Sciences, 1999. p.288-289.

KUNG JR., L.; STOKES, M.R.; LIN, C.J. Silage additives. In: BUXTON, D.R.; MUCK, R.E.; HARRISON, J.H. (Eds.) Silage Science and Technology. 1.ed. Madison: American Society of Agronomy, 2003. p.305-360.

McDONALD, P.; HENDERSON, A.R.; HERON, S.J.E. Biochemistry of silage. 2.ed. Marlow: Chalcombe Publication, 1991. 340p.

MOON, N.J. Inhibition of the growth of acid tolerant yeasts by acetate, lactate and propionate and their synergistic mixtures. Journal of Applied Bacteriology, v.55, p.453-460, 1983.

MORAN, J.P.; WEINBERG, G.; ASHBELL, Y.H. et al. A comparison of two methods for the evaluation of the aerobic stability of whole crop wheat silage. In: INTERNATIONAL SILAGE CONFEREnCE, 11., 1996, Aberystwyth. Proceedings... Aberystwyth: University of Wales Aberystwyth, 1996. p.162-163.

MUCK, R.E. Effects of corn silage inoculants on aerobic stability. Transactions of the ASAE, v.47, p.1011-1016, 2004.

NATIONAL RESEARCH COUNCIL - NRC. Nutrient requirenents of beef cattle. 7.ed. Washington, D.C.: National Academy of Science, 1996. 242p.

NUSSIO, L.G.; PAZIANI, S.F.; NUSSIO, C.M.B. Ensilagem de capins tropicais. In: REUNIÃO ANUAL DA SOCIEDADE BRASILEIRA DE ZOOTECNIA, 39., 2002, Recife. Anais... Recife: Sociedade Brasileira de Zootecnia, 2002. p.60-99.

OUDE ELFERINK, S.J.W.H.; KROONEMAN, J.; GOTTSCHAL, J.C. et al. Anaerobic conversion of lactic acid to acetic acid and 1,2-propanediol by Lactobacillus buchneri. Applied and Environmental microbiology, v.67, p.125-132, 2001.

PAHLOW, G. Role of microflora in forage conservation. In: PAHLOW, G.; HONIG, H. (Eds.) Forage conservation towards 2000. 1.ed. Braunschweig: European Grassland Federation, 1991. p.26-36.
PAHLOW, G; MUCK, R.E.; DRIEHUIS, F. et al. Microbiology of ensiling. In: BUXTON, D.R.; MUCK, R.E.; HARRISON, J.H. (Eds.) Silage science and technology. 1.ed. Madison: American Society of Agronomy, 2003. p.31-94.

PEREIRA, O.G.; ROCHA, K.D.; SILVA, A.V. Inoculantes bacterianos e enzimáticos para silagem. In: SIMPÓSIO SOBRE MANEJO ESTRATÉGICO DA PASTAGEM, 1., 2002, Viçosa, MG. Anais... Viçosa, MG: Universidade Federal de Viçosa, 2002. p.373-406.

PÖLÖNEN, I. Preservation efficiency of formic acid and benzoic acid in the ensiling of slaughterhouse by-products and their subsequent metabolism in farmed fur animals. Helsink: Faculty of Agriculture and forestry of the University of Helsink, 2000. 63p. Academic dissertation - Faculty of Agriculture and Forestry of the University of Helsink, 2000.

RANJIT, N.K.; KUNG JR., L. The effect of Lactobacillus buchneri, Lactobacillus plantarum, or a chemical preservative on the fermentation and aerobic stability of corn silage. Journal of Dairy Science, v.83, p.526-535, 2000.

RANJIT, N.K.; TAYLOR, C.C.; KUNG JR., L. Effect of Lactobacillus buchneri 40788 on the fermentation, aerobic stability and nutritive value of maize silage. Grass and Forage Science, v.57, p.73-81, 2002.

REIS, R.A.; BERNARDES, T.F.; SIQUEIRA, G.R. Tecnologia de produção e valor alimentício de silagens de capins tropicais. In: SIMPÓSIO SOBRE PRODUÇÃO E UTILIZAÇÃO DE FORRAGENS CONSERVADAS, 1., 2001, Maringá. Anais... Maringá: Universidade Estadual de Maringá, 2001. p.34-74.

SILVA, B.C.; PEREIRA, O.G.; PEREIRA, D.H. Consumo e digestibilidade aparente total dos nutrientes e ganho de peso de bovinos de corte alimentados com silagem de Brachiaria brizantha e concentrado em diferentes proporções. Revista Brasileira de Zootecnia, v.34, p.1060-1069, 2005.

SIQUEIRA, G.R.; BERNARDES, T.F.; REIS, R.A. Instabilidade aeróbia de silagens: efeitos e possibilidades de prevenção. In: REIS, R.A.; SIQUEIRA, G.R.; BERTIPAGLIA, L.M.A. (Eds.). Volumosos na produção de ruminantes. 2.ed. Jaboticabal: FUNEP, 2005. p.25-60.

SOUZA, G.B. Pré-tratamento e caracterização dos constituintes nutricionais em amostras de alimento nutricional. São Carlos: Universidade de São Paulo, 2003. 75p. Dissertação (Mestrado em Ciências - Química Analítica) Universidade de São Paulo, 2003.

SPOELSTRA, S.F.; COURTIN, M.G.; van BEERS, J.A.C. Acetic acid bacteria can initiate aerobic deterioration of maize silage. Journal of Agricultural Science, v.111, p.127-132, 1988.

WEINBERG, Z.G.; MUCK, R.E. New trends and opportunities in the development and use of inoculants for silage. FEMS Microbiology Reviews, v.19, p.53-68, 1996.

WOOLFORD, M.K. Microbiological screening of food preservatives, cold sterilants and specific antimicrobial agents as potential silage additives. Journal of the Science of Food and Agricultural, v.26, p.229-237, 1975.

YILDIRIM, Z.; AVSAR, Y.K.; YILDIRIM, M. Factors affecting the adsorption of buchnericin LB, a bacteriocin produced by Lactobacillus buchneri. Microbiological Research, v.157, p.103-107, 2002. 